\title{
Clinical characteristics of 276 hospitalized patients with coronavirus disease 2019 in Zengdu District, Hubei Province: a single- center descriptive study
}

Yiping $\mathrm{Wei}^{1+}$, Weibiao Zeng ${ }^{1+}$, Xiangyun Huang ${ }^{2}$, Junyu Li ${ }^{3}$, Xingting Qiu ${ }^{4}$, Huadong $\mathrm{Li}^{5}$, Dinghua Liu ${ }^{6}$, Zhaofeng $\mathrm{He}^{7}$, Wenzhong $\mathrm{YaO}^{8}$, Ping Huang ${ }^{9}$, Chao $\mathrm{Li}^{10}$, Min Zhu ${ }^{11}$, Chunlan Zhong ${ }^{12}$, Xingen Zhu ${ }^{13+}$ and Jiansheng $\mathrm{Liu}^{14^{*}}$

\begin{abstract}
Background: We aimed to report the epidemiological and clinical characteristics of hospitalized patients with coronavirus disease-19 (COVID-19) in Zengdu District, Hubei Province, China.

Methods: Clinical data on COVID-19 inpatients in Zengdu Hospital from January 27 to March 11, 2020 were collected; this is a community hospital in an area surrounding Wuhan and supported by volunteer doctors. All hospitalized patients with COVID-19 were included in this study. The epidemiological findings, clinical features, laboratory findings, radiologic manifestations, and clinical outcomes of these patients were analyzed. The patients were followed up for clinical outcomes until March 22, 2020. Severe COVID-19 cases include severe and critical cases diagnosed according to the seventh edition of China's COVID-19 diagnostic guidelines. Severe and critical COVID-19 cases were diagnosed according to the seventh edition of China's COVID-19 diagnostic guidelines.

Results: All hospitalized COVID-19 patients, 276 (median age: 51.0 years), were enrolled, including 262 non-severe and 14 severe patients. The proportion of patients aged over 60 years was higher in the severe group (78.6\%) than in the non-severe group $(18.7 \%, p<0.01)$. Approximately a quarter of the patients $(24.6 \%)$ had at least one comorbidity, such as hypertension, diabetes, or cancer, and the proportion of patients with comorbidities was higher in the severe group (85.7\%) than in the non-severe group $(21.4 \%, p<0.01)$. Common symptoms included fever (82.2\% [227/276]) and cough (78.0\% [218/276]). 38.4\% (106/276) of the patients had a fever at the time of admission. Most patients (94.9\% [204/276]) were cured and discharged; 3.6\% (10/276) deteriorated to a critical condition and were transferred to another hospital. The median COVID-19 treatment duration and hospital stay were 14.0 and 18.0 days, respectively.

(Continued on next page)
\end{abstract}

\footnotetext{
*Correspondence: gzliujs@126.com

†Yiping Wei, Weibiao Zeng and Xingen Zhu contributed equally to this work.

${ }^{14}$ Department of Respiratory Medicine, Ganzhou People's Hospital, No.17

Hongqi Avenue, Ganzhou City 341000, Jiangxi Province, China

Full list of author information is available at the end of the article
}

\section{$\triangle B M C$}

(c) The Author(s). 2020 Open Access This article is licensed under a Creative Commons Attribution 4.0 International License, which permits use, sharing, adaptation, distribution and reproduction in any medium or format, as long as you give appropriate credit to the original author(s) and the source, provide a link to the Creative Commons licence, and indicate if changes were made. The images or other third party material in this article are included in the article's Creative Commons licence, unless indicated otherwise in a credit line to the material. If material is not included in the article's Creative Commons licence and your intended use is not permitted by statutory regulation or exceeds the permitted use, you will need to obtain permission directly from the copyright holder. To view a copy of this licence, visit http://creativecommons.org/licenses/by/4.0/. The Creative Commons Public Domain Dedication waiver (http://creativecommons.org/publicdomain/zero/1.0/) applies to the data made available in this article, unless otherwise stated in a credit line to the data. 
(Continued from previous page)

Conclusions: Most of the COVID-19 patients in Zengdu had mild disease. Older patients with underlying diseases were at a higher risk of progression to severe disease. The length of hospital-stay and antiviral treatment duration for COVID-19 were slightly longer than those in Wuhan. This work will contribute toward an understanding of COVID-19 characteristics in the areas around the core COVID-19 outbreak region and serve as a reference for decision-making for epidemic prevention and control in similar areas.

Keywords: COVID-19, SARS-CoV-2, Echocardiography, Clinical characteristics

\section{Background}

In December 2019, a series of pneumonia cases with similar symptoms were reported in Wuhan, Hubei Province, China [1]. That pneumonia was later named coronavirus disease 2019 (COVID-19) by the World Health Organization (WHO) [2]. The causative pathogen was identified as a novel enveloped RNA beta coronavirus named severe acute respiratory syndrome coronavirus 2 (SARS-CoV-2) [3]. COVID-19 is highly contagious and spreads rapidly through human-to-human transmission [4-6]. As of March 29, 2020, there were 81,470 confirmed COVID-19 cases and 3304 deaths in China, including 67,801 confirmed cases and 3186 deaths in Hubei Province, and 721,584 confirmed cases and 33, 958 deaths worldwide. However, many infected people have not been counted owing to a lack of timely diagnosis. COVID-19 is a global pandemic. Therefore, a comprehensive and in-depth understanding of the epidemiological and clinical characteristics of COVID-19 is imperative for controlling the pandemic as soon as possible.

The number of COVID-19 cases in Wuhan was large, the spread was fast, and the fatality rate was high. Most of the clinical characteristics of COVID-19 have been summarized from the samples of patients in Wuhan [7]. Controlling the epidemic in the areas around the core COVID-19 outbreak region is an important link in blocking the spread of the disease. The Chinese government has enlisted many volunteer doctors to support hospitals in these key areas. However, there are few reports on the clinical characteristics of COVID-19 inpatients in these areas $[8,9]$. Thus, this study collected clinical data for COVID-19 inpatients in Zengdu Hospital, a community hospital supported by 95 volunteer doctors and nurses from Jiangxi Province (about 300 miles from Zengdu District). We describe the epidemiology, clinical features, laboratory findings, imaging features, and outcomes of COVID-19 inpatients in Zengdu District, which is a $3-\mathrm{h}$ drive from Wuhan City. We hope that our work will contribute toward an understanding of COVID-19 characteristics in the areas around the core COVID-19 outbreak region and provide a decision-making reference for epidemic prevention and control in similar areas.

\section{Methods}

\section{Data sources}

The study was approved by the institutional ethics board of Suizhou Zengdu Hospital, which was established by the Chinese government to treat COVID-19 patients in Zengdu District. All the patients diagnosed with COVID-19, according to the interim guidance from the WHO [10], in Zengdu Hospital from January 27 to March 11 were admitted and included in this study. The patients were followed up for clinical outcomes until March 22, 2020. Only laboratory-confirmed cases that were defined as positive based on the results of highthroughput sequencing or real-time reversetranscriptase-polymerase chain reaction (RT-PCR) assay of nasal and pharyngeal swab samples were included. These confirmatory assays for SARS-CoV-2 were performed at the Suizhou CDC in accordance with the guidelines developed by the WHO [11]. Medication and treatment measures were selected according to the scheme recommended in the guidelines and each patient's condition [12].

A team of doctors who had treated these patients extracted the recent exposure history, clinical symptoms, laboratory findings, radiologic manifestations, and clinical outcomes from patients' medical records. All patients underwent at least one chest computed tomography (CT) scan, and data were extracted after the scans were reviewed by a dedicated imaging physician. All laboratory tests were performed according to treatment needs. The researchers obtained the outcome data of transferred patients by contacting the hospitals that received these patients, and also contacted the patients by phone if anything was unclear or information necessary for the study was missing from the medical record.

\section{Study definitions}

According to the national treatment guideline, COVID19 severity was defined as mild, moderate, severe, or critical [13]. The mild type was defined as mild clinical symptoms and no radiological manifestations of pneumonia. The moderate type was defined as respiratory symptoms and pneumonia on imaging. The disease was defined as severe if one of the following criteria was met: respiratory rate of $\geq 30$ beats per minute; finger oxygen 
saturation of $\leq 93 \%$ at resting state; and arterial blood oxygen partial pressure $\left(\mathrm{PaO}_{2}\right)$ /oxygen concentration $\left(\mathrm{FiO}_{2}\right)$ of $\leq 300 \mathrm{mmHg}$. The critical type was defined as respiratory failure or shock and requirement of mechanical ventilation or intensive care unit (ICU) monitoring and treatment. Accordingly, the patients were divided into a non-severe group (mild or moderate disease type) and severe group (severe or critical disease type). Due to limited medical facilities at the Zengdu Hhospital, critical patients were transferred to hospitals with superior treatment facilities. The incubation period was defined as the interval between the patient's earliest date of exposure to the transmission source and the date of the initial symptom. For patients who had recently visited Wuhan, the earliest date of exposure was estimated as the median date of their stay in Wuhan; for patients who had been in contact with people returning from Wuhan, the earliest date of exposure was considered to be the earliest contact date, the earliest date of exposure was considered to be the earliest contact date. Fever was defined as an axillary temperature of $\geq 37.5^{\circ} \mathrm{C}$. Lymphopenia, eosinopenia, and thrombocytopenia were defined as lymphocyte, eosinophil, and platelet counts of less than 1500,100, and 150,000 of the corresponding cells per cubic millimeter. The smoking index was equal to the product of the number of cigarettes per day and smoking years. The length of COVID-19 treatment was defined as the time interval from patient admission to the meeting of the cure and discharge criteria of the Chinese management guidelines for COVID-19 (version 6.0) [12]. The cure and discharge criteria were as follows: Normal body temperature for more than 3 days; significantly improved respiratory symptoms; significantly improved acute exudative lesions on pulmonary imaging; and two consecutive negative results of the nucleic acid tests of sputum, nasopharyngeal swabs, and other respiratory tract samples.

\section{Study outcomes}

The primary composite end points were discharge from the hospital owing to being cured and transfer to another hospital because of condition deterioration. The secondary end points were cure or discharge rate and the length of hospital stay.

\section{Statistical analyses}

Statistical analyses were performed with SPSS (v.18.0; SPSS Inc., Chicago, IL, USA). Continuous variables are described as median values and interquartile ranges (IQRs), and categorical variables are reported as numbers and percentages. We used the Mann-Whitney $U$ test, $x^{2}$ test, or Fisher's exact test to compare differences between the two groups. A two-sided $\alpha$ of less than 0.05 was considered statistically significant.

\section{Results}

\section{Demographic and clinical characteristics}

We obtained data on the demographic characteristics, symptoms, and outcomes for 276 patients hospitalized in Suizhou Zengdu Hhospital as of March 11, 2020. The severe group included 14 (5.1\%) patients while the nonsevere group included 262 (94.9\%) patients. The demographic and clinical characteristics of the patients are shown in Table 1. Forty-three (15.6\%) of the 276 patients had visited Wuhan within 14 days before the study enrollment; $60.1 \%(166 / 276)$ of the patients had come into contact with people who had travelled to Wuhan or were diagnosed with COVID-19. The remaining 67 patients reported they had not been to Wuhan, and it was unclear how these patients had been exposed to the transmission source; none of the patients had a history of exposure to the Huanan seafood wholesale market or a wild animal. The incubation period calculated based on the data from 71 patients with a known exposure time was 6 days (IQR, 4-7 days). The longest incubation period was 20 days. A nurse in the fever clinic of Suizhou Zengdu Hhospital was the only medical staff included in the study.

The median age of the patients was 51 years (IQR, 41-58 years). The patients in the severe group were significantly older than those in the non-severe patients (median age: 65 years [IQR, 60.0-72.8 years] vs 50 years [IQR, 39.0-57.0 years], $p<0.01$ ). Male patients accounted for $56.2 \%$ of all patients. A history of smoking was noted for $12.8 \%$ of the 220 patients with smoking index data. The median body mass index (BMI) of all the patients included was 23.7 (IQR, 22.0-25.4). The most common symptom of COVID19 was fever, which was observed in $82.2 \%(227 / 276)$ of the patients. The other common symptoms were cough $(78.0 \%, 218 / 276)$, fatigue $(51.1 \%, 141 / 276)$, sputum production $(49.6 \%, 137 / 276)$, and shortness of breath $(15.2 \%, 42 / 276)$. Fever at the time of admission was noted in $38.4 \%(42 / 276)$ of the patients, while fever during hospitalization was noted in $75.0 \%$ (207/ 276 ) of the patients. At least one comorbidity was reported in $24.6 \%(68 / 276)$ of the patients, with the most common comorbidity being hypertension $(17.0 \%$, 47/276). Most of the severe patients $(85.7 \%, 12 / 14)$ had at least one comorbidity; this percentage was significantly higher than that among the non-severe patients $(21.4 \%, 56 / 262)$.

\section{Radiologic and laboratory findings}

Table 2 shows the results of radiology and laboratory tests at admission. All 276 patients underwent CT at admission, and abnormal results were obtained for 95.7\% (264/276) of the patients. The most common chest CT findings were bilateral patchy shadows 
Table 1 Clinical characteristics of 276 patients with COVID-19 on admission

\begin{tabular}{|c|c|c|c|c|}
\hline \multirow[t]{2}{*}{ Characteristic } & \multirow{2}{*}{$\begin{array}{l}\text { All Patients } \\
(N=276)\end{array}$} & \multicolumn{2}{|l|}{ Disease Severity $^{a}$} & \multirow[t]{2}{*}{$p$ value } \\
\hline & & Non-severe $(N=262)$ & Severe $(N=14)$ & \\
\hline \multicolumn{5}{|l|}{ Age } \\
\hline Median (IQR) - yr & $51.0(41.0-58.0)$ & $50.0(39.0-57.0)$ & $65.0(60.0-72.8)$ & $<0.01$ \\
\hline \multicolumn{5}{|l|}{ Distribution — no./total no. (\%) } \\
\hline $0-19 y r$ & $4 / 276(1.4)$ & $4 / 262(1.5)$ & 0 & 0.50 \\
\hline $20-59 y r$ & 212/276 (76.8) & 209/262 (79.8) & $3 / 14(21.4)$ & $<0.01$ \\
\hline$>60 \mathrm{yr}$ & $60 / 276(21.7)$ & 49/262 (18.7) & 11/14 (78.6) & $<0.01$ \\
\hline Male sex-no./total no. (\%) & 155/276 (56.2) & $145 / 262(55.3)$ & 10/14 (71.4) & 0.24 \\
\hline Smoking Index ${ }^{\mathrm{b}}-$ no./total no. (\%) & & & & 0.57 \\
\hline 0 & $192 / 220(87.2)$ & 182/208 (87.5) & 10/12 (83.3) & \\
\hline $1-199$ & $7 / 220(3.2)$ & $7 / 208(3.4)$ & $0 / 12(0)$ & \\
\hline 200-399 & $6 / 220(2.7)$ & $5 / 208(2.4)$ & $1 / 12(8.3)$ & \\
\hline$\geq 400$ & 15/220 (6.8) & $14 / 208(6.7)$ & $1 / 12(8.3)$ & \\
\hline Median BMI (IQR) & $23.7(22.0-25.4)$ & $23.7(21.8-25.4)$ & $24.2(22.5-25.5)$ & 0.55 \\
\hline \multicolumn{5}{|l|}{ Exposure to source of transmission within past 14 days - no./total no. ${ }^{c}$} \\
\hline Recently visited Wuhan & $43 / 276(15.6)$ & $42 / 262(16.0)$ & $1 / 14(7.1)$ & 0.37 \\
\hline Had contact with people who visited Wuhan or were diagnosed with COVID-19 & $166 / 276(60.1)$ & 157/262 (59.9) & $9 / 14(64.3)$ & 0.75 \\
\hline Contact with wildlife & 0 & 0 & 0 & \\
\hline Median incubation period (IQR) - days ${ }^{d}$ & $6.0(4.0-9.0)$ & $6.0(4.0-9.0)$ & $6.0(5.0-9.0)$ & 0.54 \\
\hline \multicolumn{5}{|l|}{ Fever on admission } \\
\hline Patients — no./total no. (\%) & 106/276 (38.4) & $99 / 262(37.8)$ & $7 / 14(50.0)$ & 0.36 \\
\hline Median temperature $(\mathrm{IQR})-{ }^{\circ} \mathrm{C}$ & $37.2(36.6-37.9)$ & $37.2(36.6-37.9)$ & $37.6(36.6-38.1)$ & 0.56 \\
\hline \multicolumn{5}{|l|}{ Distribution of temperature — no./total no. (\%) } \\
\hline$<37.5^{\circ} \mathrm{C}$ & $170 / 276(61.6)$ & $163 / 262(62.2)$ & $7 / 14(50.0)$ & 0.37 \\
\hline $37.5-38.0^{\circ} \mathrm{C}$ & $54 / 276(19.6)$ & $51 / 262(19.5)$ & $3 / 14(21.4)$ & 0.86 \\
\hline $38.1-39.0^{\circ} \mathrm{C}$ & $41 / 276(14.9)$ & $39 / 262(14.9)$ & $2 / 14(14.3)$ & 0.95 \\
\hline$>39.0^{\circ} \mathrm{C}$ & $11 / 276(4.0)$ & $9 / 262(3.4)$ & 2/14 (14.3) & 0.04 \\
\hline \multicolumn{5}{|l|}{ Fever during hospitalization } \\
\hline Patients — no./total no. (\%) & 207/276 (75.0) & $195 / 262(74.4)$ & $12 / 14(85.7)$ & 0.34 \\
\hline Median highest temperature $(\mathrm{IQR})-{ }^{\circ} \mathrm{C}$ & $38.2(37.5-38.9)$ & $38.2(37.4-38.9)$ & $38.9(8.3-39.6)$ & 0.47 \\
\hline \multicolumn{5}{|l|}{ Distribution of temperature — no./total no. (\%) } \\
\hline$<37.5^{\circ} \mathrm{C}$ & $69 / 276(25.0)$ & $67 / 262(25.6)$ & $2 / 14(14.3)$ & 0.34 \\
\hline $37.5-38.0^{\circ} \mathrm{C}$ & $57 / 276(20.7)$ & $56 / 262(21.4)$ & $1 / 14(7.1)$ & 0.20 \\
\hline $38.1-39.0^{\circ} \mathrm{C}$ & 107/276 (38.8) & $103 / 262(39.3)$ & $4 / 14(28.6)$ & 0.41 \\
\hline$>39.0^{\circ} \mathrm{C}$ & 43/276 (15.6) & $36 / 262(13.7)$ & $7 / 14(50.0)$ & $<0.01$ \\
\hline \multicolumn{5}{|l|}{ Symptoms — no./total no. (\%) } \\
\hline Fever & $227 / 276(82.2)$ & 219/262 (84.4) & $8 / 14(57.1)$ & 0.01 \\
\hline Conjunctival congestion & $2 / 276(0.7)$ & $2 / 262(0.8)$ & 0/14 (0) & 0.90 \\
\hline Nasal congestion & $8 / 276(2.9)$ & $8 / 262(3.1)$ & $0 / 14(0)$ & 0.66 \\
\hline Headache & 24/276 (8.7) & 22/262 (8.4) & 2/14 (14.3) & 0.78 \\
\hline Cough & 218/276 (78.0) & 204/262 (77.9) & $14 / 14(100.0)$ & 0.02 \\
\hline Sore throat & 26/276 (9.4) & 23/262 (8.8) & $3 / 14(21.4)$ & 0.27 \\
\hline Sputum production & 137/276 (49.6) & $127 / 262(48.5)$ & 10/14 (71.4) & 0.16 \\
\hline Fatigue & $141 / 276(51.1)$ & $133 / 262(50.8)$ & $8 / 14(57.1)$ & 0.64 \\
\hline
\end{tabular}


Table 1 Clinical characteristics of 276 patients with COVID-19 on admission (Continued)

\begin{tabular}{|c|c|c|c|c|}
\hline \multirow[t]{2}{*}{ Characteristic } & \multirow{2}{*}{$\begin{array}{l}\text { All Patients } \\
(N=276)\end{array}$} & \multicolumn{2}{|l|}{ Disease Severity ${ }^{a}$} & \multirow[t]{2}{*}{$p$ value } \\
\hline & & Non-severe $(N=262)$ & Severe $(N=14)$ & \\
\hline Hemoptysis & $1 / 276(0.4)$ & $0 / 262(0)$ & $1 / 14(7.1)$ & 0.06 \\
\hline Shortness of breath & $42 / 276(15.2)$ & $36 / 262(13.7)$ & $6 / 14(42.9)$ & $<0.01$ \\
\hline Nausea or vomiting & 23/276 (8.3) & 20/262 (7.6) & $3 / 14(21.4)$ & 0.10 \\
\hline Diarrhea & $6 / 276(2.2)$ & $5 / 262(1.9)$ & $1 / 14(7.1)$ & 0.71 \\
\hline Myalgia or arthralgia & 26/276 (9.4) & $24 / 262(9.2)$ & 2/14 (14.3) & 0.84 \\
\hline \multicolumn{5}{|l|}{ Comorbidities — no./total no. (\%) } \\
\hline Any & $68 / 276(24.6)$ & $56 / 262(21.4)$ & $12 / 14(85.7)$ & $<0.01$ \\
\hline Hypertension & $47 / 276(17.0)$ & $39 / 262(14.9)$ & $8 / 14(57.1)$ & $<0.01$ \\
\hline Chronic obstructive pulmonary disease & $7 / 276(2.5)$ & $5 / 262(1.93)$ & $2 / 14(14.3)$ & 0.04 \\
\hline Diabetes & $14 / 276(5.1)$ & $12 / 262(4.6)$ & $2 / 14(14.3)$ & 0.32 \\
\hline Coronary heart disease & $12 / 276(4.0)$ & $8 / 262(5.2)$ & 4/14 (28.6) & $<0.01$ \\
\hline Cerebrovascular disease & $6 / 276(2.2)$ & $5 / 262(2.0)$ & $1 / 14(7.1)$ & 0.71 \\
\hline Cancer ${ }^{e}$ & $3 / 276(1.1)$ & $2 / 262(0.8)$ & $1 / 14(7.1)$ & 0.36 \\
\hline
\end{tabular}

IQR interquartile range; $B M I$ body mass index; Covid-19 coronavirus disease 2019

a Severe group needs to meet one of the following criteria: respiratory rate $\geq 30$ beats per minute; finger oxygen saturation $\leq 93 \%$ at resting state; arterial blood oxygen partial pressure $\left(\mathrm{PaO}_{2}\right)$ /oxygen concentration $\left(\mathrm{FiO}_{2}\right) \leq 300 \mathrm{mmHg}$; has respiratory failure or shock; required mechanical ventilation or intensive care unit monitoring and treatment

b Smoking index was equal to the product of the number of cigarettes per day and years of smoking

' 95 patients were unsure if they had been exposed to a source of transmission

d Incubation period for 205 people could not be determined

e Included any kind of cancer

$(84.1 \%, 232 / 276)$ and ground-glass-like shadows $(80.1 \%, 221 / 276)$. Figure 1 shows typical ground-glass shadows and bilateral patchy shadows in two patients.

According to the results of the first examination after admission, 30.1\% (83/276), 75.0\% (204/276), and 31.5\% $(87 / 276)$ of the patients had leukopenia, lymphocytopenia, and thrombocytopenia, respectively. Lymphocytopenia and thrombocytopenia were more obvious in the severe group compared to that in the non-severe group. The C-reactive protein levels were elevated in $60.9 \%$ $(162 / 266)$ of the patients; the erythrocyte sedimentation rate of $90.0 \%(180 / 201)$ of patients and D-dimer levels of $53.7 \%(123 / 229)$ of patients were also elevated. Elevated procalcitonin, creatine kinase, alanine aminotransferase, aspartate aminotransferase, and myoglobin levels were observed in $2.5,11.1,14.2,22.3$, and $8.0 \%$ of patients, respectively.

\section{Clinical outcomes}

As shown in Table 3, most of the patients (94.9\%, 262/ 276) were cured and discharged from the hospital. Ten out of $276(3.6 \%)$ patients, all of whom belonged to the severe group, showed condition deterioration to a critical status and were transferred to Suizhou Central Hospital, a superior hospital. Eventually, five of them died and five survived. All five people who died received endotracheal intubation; one of the five survivors received endotracheal intubation, which was removed 20 days later. The remaining four only received non- invasive ventilator treatment; $1.4 \%(4 / 276)$ of the patients were transferred to Suizhou Central Hospital for non-COVID-19 reasons and were shortly discharged from the hospital. The median lengths of COVID-19 treatment and hospital stay were 14.0 days (IQR, 11.018.0 days) and 18.0 days (IQR, 15.0-24.0 days), respectively.

\section{Discussion}

Understanding the clinical characteristics of COVID-19 inpatients in the areas around the core COVID-19 outbreak region is very important for controlling the spread of COVID-19 and decision-making for epidemic control. Our study on 276 inpatients in Zengdu Hhospital confirms that COVID-19 patients in the areas surrounding the core COVID-19 outbreak region showed mainly mild and moderate illness with fever and lymphocytopenia as the main clinical features. Older patients (age $>60$ years) or those with underlying comorbidities are at higher risk of deteriorating to critical status. The length of hospital-stay and antiviral treatment duration for COVID-19 were slightly longer than those in Wuhan.

All patients who tested positive for COVID-19 by RTPCR in the study region were admitted to the hospital, regardless of the severity of the patients' condition. There were several reasons why our hospital established such an admission standard. First, at that time, the outbreak was still in the early stage. The understanding of the epidemic situation in Zengdu District, a residential 
Table 2 Radiographic and laboratory findings of 276 patients with COVID-19 on admission to hospital ${ }^{a}$

\begin{tabular}{|c|c|c|c|c|}
\hline \multirow[t]{2}{*}{ Variable } & \multirow{2}{*}{$\begin{array}{l}\text { All Patients } \\
(\mathrm{N}=276)\end{array}$} & \multicolumn{2}{|l|}{ Disease Severity } & \multirow{2}{*}{$\begin{array}{l}p \\
\text { value }\end{array}$} \\
\hline & & Non-severe $(\mathrm{N}=262)$ & Severe $(N=14)$ & \\
\hline Abnormalities on chest CT — no./total no. (\%) & $264 / 276(95.7 \%)$ & $250 / 262(95.4 \%)$ & $14 / 14(100.0 \%)$ & 0.53 \\
\hline Ground-glass opacity & $221 / 276(80.1 \%)$ & $209 / 262(79.8 \%)$ & 12/14 (85.7\%) & 0.45 \\
\hline Local patchy shadowing & $17 / 276(6.4 \%)$ & $17 / 262(6.5 \%)$ & 0 & 0.40 \\
\hline Bilateral patchy shadowing & 232/276 (84.1\%) & $220 / 262(84.0 \%)$ & 12/14 (85.7\%) & 0.41 \\
\hline Interstitial abnormalities & $40 / 276(14.5 \%)$ & $37 / 262(14.1 \%)$ & $3 / 14(21.4 \%)$ & 0.54 \\
\hline \multicolumn{5}{|l|}{ Laboratory findings } \\
\hline \multicolumn{5}{|l|}{ White-cell count } \\
\hline Median (IQR) - per $\mathrm{mm}^{3}$ & $4700(3800-6100)$ & $4700(3800-6000)$ & $6000(4000-7100)$ & 0.27 \\
\hline \multicolumn{5}{|l|}{ Distribution — no./total no. (\%) } \\
\hline$>10,000$ per $\mathrm{mm}^{3}$ & $16 / 276(5.8)$ & $15 / 262(5.7)$ & $1 / 14(7.1)$ & 0.70 \\
\hline$<4000$ per $\mathrm{mm}^{3}$ & $83 / 276(30.1)$ & $79 / 262(30.2)$ & $4 / 14(28.6)$ & 0.67 \\
\hline \multicolumn{5}{|l|}{ Lymphocyte count } \\
\hline Median (IQR) - per $\mathrm{mm}^{3}$ & $1100(800-1500)$ & $1100(800-1500)$ & $700(400-800)$ & $<0.01$ \\
\hline \multicolumn{5}{|l|}{ Distribution - no./total no. (\%) } \\
\hline$<1500$ per $\mathrm{mm}^{3}$ & $204 / 276(75.0)$ & 193/262 (73.7) & $11 / 14(78.6)$ & 0.72 \\
\hline \multicolumn{5}{|l|}{ Eosinocyte count } \\
\hline Median (IQR) - per $\mathrm{mm}^{3}$ & $0.01(0-0.03$ & $0.01(0-0.03)$ & $0(0-0.01)$ & 0.19 \\
\hline \multicolumn{5}{|l|}{ Distribution — no./total no. (\%) } \\
\hline$<100$ per $\mathrm{mm}^{3}$ & $126 / 276(45.7)$ & $117 / 262(44.7)$ & $9 / 14(64.3)$ & 0.33 \\
\hline \multicolumn{5}{|l|}{ Platelet count } \\
\hline Median (IQR) - per $\mathrm{mm}^{3}$ & $177,000(140000-221,000)$ & $177,000(141000-222,000)$ & $136,000(112000-196,000)$ & 0.03 \\
\hline \multicolumn{5}{|l|}{ Distribution — no./total no. (\%) } \\
\hline$<150,000$ per $\mathrm{mm}^{3}$ & $87 / 276(31.5)$ & $80 / 262(30.5)$ & $7 / 14(50.0)$ & $<0.01$ \\
\hline Median hemoglobin $(\mathrm{QQR})-\mathrm{g} / \mathrm{dl}$ & $131.5(123.0-143.0)$ & $132.0(124.0-143.0)$ & $130.0(100.0-139.0)$ & 0.19 \\
\hline \multicolumn{5}{|l|}{ Distribution of other findings - no./total no. (\%) } \\
\hline C-reactive protein $\geq 10 \mathrm{mg} / \mathrm{L}$ & $162 / 266(60.9)$ & $152 / 252(60.3)$ & 10/14 (71.4) & 0.30 \\
\hline Procalcitonin $\geq 0.5 \mathrm{ng} / \mathrm{ml}$ & $6 / 240(2.5)$ & $5 / 226(2.2)$ & $1 / 14(7.1)$ & 0.31 \\
\hline Lactate dehydrogenase $\geq 250 \mathrm{U} / \mathrm{L}$ & 31/93 (33.3) & $27 / 88(30.7)$ & 4/14 (28.6) & 0.57 \\
\hline Aspartate aminotransferase $>40 \mathrm{U} / \mathrm{L}$ & $39 / 274(14.2)$ & $34 / 260(13.1)$ & $5 / 14(35.7)$ & 0.03 \\
\hline Alanine aminotransferase $>40 \mathrm{U} / \mathrm{L}$ & $61 / 274(22.3)$ & $58 / 260(22.3)$ & $3 / 14(21.4)$ & 0.62 \\
\hline Total bilirubin $>17.1 \mu \mathrm{mol} / \mathrm{L}$ & $43 / 274(15.7)$ & $42 / 260(16.2)$ & $1 / 14(7.1)$ & 0.32 \\
\hline Creatine kinase $\geq 200 \mathrm{U} / \mathrm{L}$ & $9 / 81(11.1)$ & $7 / 78(9.0)$ & $2 / 3(66.7)$ & 0.03 \\
\hline Creatinine $\geq 115 \mu \mathrm{mol} / \mathrm{L}$ & $6 / 274(2.2)$ & $3 / 260(1.2)$ & $3 / 14(21.4)$ & $<0.01$ \\
\hline D-dimer > 0.5 mg/L & $123 / 229(53.7)$ & $115 / 219(52.5)$ & $8 / 10(80.0)$ & 0.08 \\
\hline Myohemoglobin > $80 \mu \mathrm{g} / \mathrm{L}$ & 18/204 (8.0) & 13/191 (6.8) & $5 / 13(38.5)$ & $<0.01$ \\
\hline Erythrocyte sedimentation rate $>20 \mathrm{~mm} / \mathrm{h}$ & $180 / 201(90.0)$ & 169/190 (88.9) & $11 / 11(100.0)$ & 0.29 \\
\hline
\end{tabular}

${ }^{a}$ Lymphocytopenia was defined as a lymphocyte count less than 1500 per cubic millimeter. Eosinopenia was defined as an eosinocyte count of less than 100 per cubic millimeter. Thrombocytopenia was defined as a platelet count of less than 150,000 per cubic millimeter. These are results of the first examination after admission

area approximately $3 \mathrm{~h}$ away from the core COVID-19 outbreak region, was very limited, and there was no clear evidence to determine which patients could be treated at home. Second, the representative area of Zengdu District was a key area to control the spread of the epidemic; therefore, it was necessary to treat as many diagnosed patients as possible. Third, at that time, Zengdu Hhospital was supported by 98 Jiangxi volunteer doctors (including most of the authors of this article) and extensive medical equipment. Hence, there were sufficient medical 


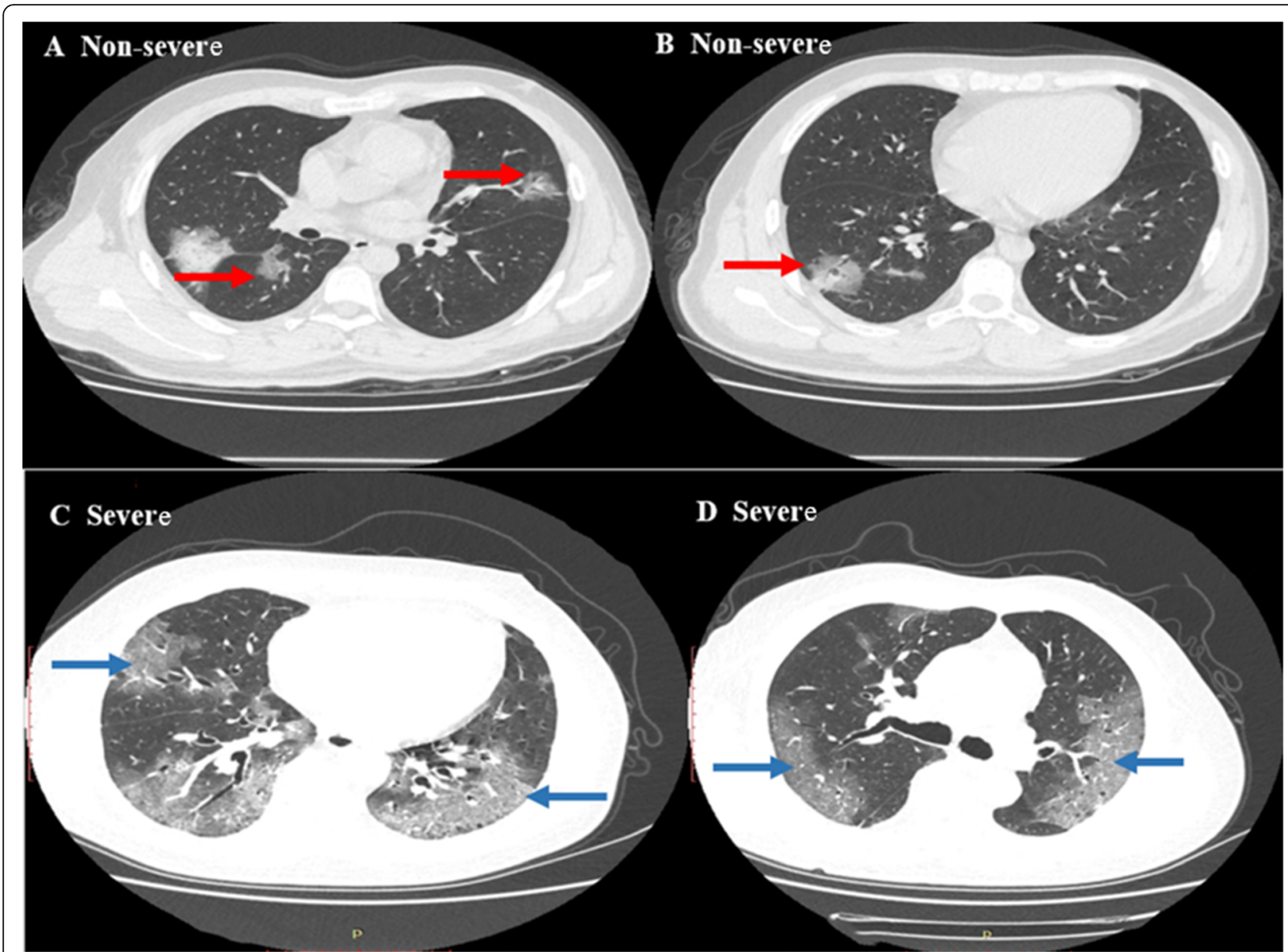

Fig. 1 Typical chest computed tomography imaging of COVID-19 patients. Panels $\mathbf{a}$ and $\mathbf{b}$ show chest computed tomography images from a middle-aged male with non-severe COVID-19 at time of admission, showing several scattered ground-glass opacities (A, B the red arrow point). Panel $\mathbf{c}$ and $\mathbf{d}$ show chest computed tomography imaging findings from a middle-aged male with severe COVID-19 at time of admission, showing bilateral patchy shadows and consolidation (C, D the blue arrow point). COVID-19: coronavirus disease 2019

resources to treat all the diagnosed patients. Our admission criteria were formulated under such special circumstances, although this admission standard was different from the current international standard. Moreover, compared to studies in which only seriously ill COVID-19 patients were admitted, our admission criteria better reflect the disease characteristics in the area around the outbreak point, so as to provide a decision-making reference for hospitals in the residential area to decide which patients should stay at home for observation and which high-risk patients should be hospitalized in a timely manner.

The patients in Zengdu area show mainly showed mild and moderate illness, with a few patients showing severe

Table 3 Clinical outcomes of patients with COVID-19

\begin{tabular}{|c|c|c|c|c|}
\hline \multirow[t]{2}{*}{ Variable } & \multirow{2}{*}{$\begin{array}{l}\text { All Patients } \\
(\mathrm{N}=276)\end{array}$} & \multicolumn{2}{|l|}{ Disease Severity } & \multirow[t]{2}{*}{$p$ value } \\
\hline & & Non-severe $(\mathrm{N}=262)$ & Severe $(N=14)$ & \\
\hline \multicolumn{5}{|l|}{ Clinical outcomes — no. (\%) } \\
\hline Cured and discharged from hospital & 262/276 (94.9) & 258/262 (98.5) & 4/14 (28.6) & $<0.01$ \\
\hline Deteriorated to critical and transferred to a hospital & 10/276 (3.6) & $0 / 262(0)$ & 10/14 (71.4) & $<0.01$ \\
\hline Transferred to a hospital for other reasons & $4 / 276(1.4)$ & $4 / 262(1.5)$ & $0 / 14(0)$ & 0.81 \\
\hline Median length of treatment for COVID-19 (IQR) - days $^{\text {a }}$ & $14.0(11.0-18.0)$ & $14.0(11.0-18.0)$ & $16.0(15.0-17.0)$ & 0.15 \\
\hline Median length of hospitalization (IQR) - days $^{\text {a }}$ & $18.0(15.0-24.0)$ & $18.0(15.0-24.0)$ & $21.5(14.0-21.0)$ & 0.44 \\
\hline
\end{tabular}

a 10 patients who deteriorated to critical status and 4 patients who were transferred to other hospital for other reasons were not included 
and critical illness. In Wuhan, as the site with the most serious COVID-19 infection in China, many patients did not get timely diagnosis and treatment initially, and medical resources were insufficient to accommodate the sudden burst of patients. As a result, the proportion of severe cases reached $15.0-30.0 \%[14,15]$, while the rate of severe disease in other regions was $3-10 \%[16,17]$, similar to $5.1 \%$ in this study. This may be because, with the deepening of the understanding of COVID-19 and the formulation of relevant guidelines [18, 19], many patients were diagnosed and treated in a timely manner without deteriorating into severe disease. Besides, the difference in admission criteria was also a reason why the rate of severe disease in this study was significantly lower than that in Wuhan or abroad.

The early common symptoms of COVID-19 patients include fever, cough, sputum, and other symptoms of lower respiratory tract infection. As the most common symptom, in general, more than $80 \%$ of patients have a fever, but only $38.4 \%$ of the patients had a fever at the time of admission, which shows that the fever in many patients was intermittent. It also means a large number of patients with intermittent fever will be set free if instant body temperature readings are the only measure used for screening $[2,20]$. The proportion of fever in critically ill patients increases significantly after hospitalization, and most of these new fever cases may be caused by secondary infection, so it is necessary for severe patients to receive antibiotics to prevent secondary infection [13].

COVID-19 patients over 60 years old were more likely to show deterioration into critical illness. Previous studies on severe acute respiratory syndrome (SARS) and Middle East Respiratory Syndrome (MERS) have confirmed that age was an important predictor of poor prognosis $[20,21]$, and similar conclusions were obtained for COVID-19 [22]. Data obtained by Nanshan Zhong et al. [23] and Zhongliang Wang et al. [14] showed that the age of severe patients was significantly older than that of non-severe patients. Consistent with these findings, among the patients we collected, the median age of severe patients was 65 years, while that of non-severe patients was 50 years. In addition, about $78.6 \%$ of the severe patients were more than 60 years old. These studies have shown that older COVID-19 patients have a poor prognosis.

COVID-19 patients with comorbidities were also likely to show deterioration [24]. The studies by Nanshan Zhong et al. and DaweiWang et al. [22] both showed high proportions of comorbidities in severe patients. A WHO survey reported that people with comorbidities had a higher risk of severe disease [25]. In a recent retrospective study of 25 death cases with COVID-19 [24], all of the deceased patients have comorbidities, which were considered to be one of the most important risk factors for death. In this study, $85.7 \%$ of the severe patients had comorbidities. This may be due to abnormal immune function and increased susceptibility to SARS-CoV-2 in patients with comorbidities [26, 27]. In addition, COVID-19 damage to the lungs can aggravate some comorbidities, such as chronic obstructive pulmonary disease. Antiviral drugs and glucocorticoids also have limited benefits for patients with comorbidities.

In terms of laboratory tests, $75 \%$ of patients had lymphopenia, and more obvious findings were noted in severe patients. The novel coronavirus can induce a cytokine storm and inhibit the generation of lymphocytes [28, 29], so lymphopenia is very common in patients with COVID19. The low absolute value of lymphocytes can be used as a reference indicator for clinical diagnosis of novel coronavirus infections [6]. Lymphocytes showed a pronounced decline in severe patients than in non-severe patients, indicating that the degree of lymphocyte decline can be used to assess the severity of the disease [30], and that continuous decline of lymphocytes is also one of the indicators of disease deterioration [13]. In the absence of nucleic acid detection and CT, this can be an important tool for determining the severity of the disease. The length of hospital stay in this study was slightly longer than that in Wuhan, which was 11-12 days [23, 31]. This contradicted the finding that the length of hospitalization is positively related to disease severity because COVID-19 severity in this study was significantly lower than that in Wuhan. However, the allocation of medical resources is also an important factor affecting the length of hospitalization. The number of infected patients in Wuhan was large and medical resources were scarce, so the hospital had to discharge inpatients as soon as possible to treat newly admitted patients. The inpatient data collected in this study were from a community hospital that was supported by many Jiangxi doctor volunteers and medical supplies, which ensured sufficient medical resources. The characteristics of inpatients under this special medical setup were different from those at other hospitals. In particular, after the local epidemic is mostly controlled, some wastage of medical resources may be inevitable. For example, patients were allowed to stay in the hospital for some time to recover even after meeting the discharge criteria for COVID-19, which was not possible in the hospital in Wuhan. This was also the reason why the length of treatment for COVID-19 (14 days) is significantly shorter than the length of hospitalization (18 days). In addition, hospitals in Wuhan only accept patients who have been diagnosed as showing COVID-19, while hospitals outside Wuhan admitted many patients who were not diagnosed at admission and were also hospitalized for the 1-3 days it took for nucleic acid test results to arrive. Three studies from regions with sufficient medical resources [32-34], namely 
Taizhou, Guangdong, and Shenzhen, can support our hypotheses since their median hospital stays were 18 days, 20 days, and 20 days, respectively, which were close to the results of this study.

This study has several limitations. First, since it is a retrospective study with a limited number of patients, some conclusions need to be verified by studies with more rigorous design and larger samples. Second, Zengdu Hhospital was a community hospital, and most of the critically ill patients had to be transferred to superior hospitals for treatment. we are temporarily unable to get information on the followup treatment and complications of these patients. Third, when calculating the incubation period, we excluded the unclear contact date, resulting in fewer patients included, and the potential memory bias will also affect our results. Fourth, our admission criteria were different from the current internationally recognized criteria, which limits comparability with other studies. However, our admission criteria were set in high-risk areas at the early stage of the epidemic to avoid the spread of the epidemic, which was essential and important. In addition, only PCR-confirmed COVID-19 patients were included in this study and asymptomatic infections without PCR confirmation were omitted, so the characteristics we described are only suitable for PCR-confirmed COVID-19 patients.

\section{Conclusions}

Most of the COVID-19 patients in Zengdu area had mild disease. Older patients with underlying comorbidities had a high risk of progressing to severe disease. A large number of patients with intermittent fever will be omitted by the temperature checks that are currently widely being deployed. The length of hospitalization and antiviral treatment for COVID-19 were slightly longer than those in the Wuhan area. This work will contribute to our understanding of the disease characteristics in the areas around the COVID-19 core outbreak point and provide reference data for decision-making for epidemic prevention and control in such special areas.

\section{Abbreviations \\ COVID-19: Coronavirus disease-19; SARS-CoV-2: Severe acute respiratory syndrome coronavirus 2; CDC: Centers for Disease Control and Prevention; WHO: World Health Organization; RT-PCR: Real-time reverse-transcriptase- polymerase chain reaction; CT: Computed tomography; BMI: Median body mass index; IQR: Interquartile ranges; SARS: Severe acute respiratory syndrome; MERS: Middle East Respiratory Syndrome; ACE: Angiotensin- converting enzyme}

\section{Acknowledgements}

We thank all the medical staff who participated in treating patients and all the patients enrolled in this study. The data of these patients have been published for the first time. All the authors who are not from Zengdu Hospital are volunteers from different hospitals in Jiangxi Province, and these volunteers work with doctors and nurses from Zengdu Hospital to fight against COVID-19. Special thanks to the 82 other volunteers from Jiangxi Province for their contributions.

\section{Declarations}

Not applicable.

\section{Authors' contributions}

LJS, ZXG, WYP and HXY designed the study. HP, LC, ZM, LHD, and LDH were responsible for collecting the epidemiological and clinical data; QXT examined the CT images and extracted the data; HZF, LJY, and ZCL were responsible for processing the statistical data; and ZWB, YWZ, and LHD wrote the paper. ZXG participated in the design and revision of the manuscript. All authors read and approved the final manuscript.

\section{Funding}

This research did not receive any specific grant from funding agencies in the public, commercial, or not-for-profit sectors.

\section{Availability of data and materials}

The datasets used and/or analyzed during the current study are available from the corresponding author on reasonable request.

\section{Ethics approval and consent to participate}

This study was approved by the Ethics Committee of Suizhou Zengdu Hospital. Written informed consent has been obtained from all participants. The data used in this study was anonymized before its use.

\section{Consent for publication}

Not applicable.

\section{Competing interests}

The authors declare that they have no competing interests to disclose.

\section{Author details}

'Department of Thoracic Surgery, The Second Affiliated Hospital of Nanchang University, Nanchang, China. ${ }^{2}$ Suizhou Zengdu Hospital, Suizhou, China. ${ }^{3}$ Department of Radiotherapy, Jiangxi Cancer Hospital, NanChang, China. ${ }^{4}$ Department of CT\&MRI, The First Affiliated Hospital of Gannan Medical University, Ganzhou, China. ${ }^{5}$ Department of Respiratory Medicine, Chongyi County People's Hospital, Ganzhou, China. ${ }^{6}$ Department of Critical Medicine, Ganzhou Tumor Hospital, Ganzhou, China. ${ }^{7}$ Department of Critical Care Medicine, Dingnan People's Hospital, Dingnan, China. ${ }^{8}$ Department of Critical Medicine, Anyuan People's Hospital, Ganzhou, China. ${ }^{9}$ Department of Infectious Disease, Xingguo People's Hospital, Ganzhou, China. ${ }^{10}$ Department of Respiratory Medicine, Jiangxi Province Hospital of Integrated Chinese and Western Medicine, Nanchang, China. ${ }^{11}$ Department of General Practice, The First People's Hospital of Fuzhou, Fuzhou, China. ${ }^{12}$ Department of Pediatric Neurology, Ganzhou Women's and Children's Hospital of Jiangxi Province, Ganzhou, China. ${ }^{13}$ Neurosurgery Department, The Second Affiliated Hospital of Nanchang University, Nanchang, China. ${ }^{14}$ Department of Respiratory Medicine, Ganzhou People's Hospital, No.17 Hongqi Avenue, Ganzhou City 341000, Jiangxi Province, China.

Received: 2 May 2020 Accepted: 14 July 2020

Published online: 29 July 2020

References

1. Paules C, Marston H, Fauci AJJ. Coronavirus infections-more than just the common cold. JAMA. 2020. https://doi.org/10.1001/jama.2020.0757.

2. WHO. Clinical management of severe acute respiratory infection when novel coronavirus (2019-nCoV) infection is suspected: interim guidance. In: World Health Organization; 2020. https://www.who.int/docs/default-source/ coronaviruse/clinical-management-of-novel-cov.pdf. Accessed 28 Jan 2020.

3. WHO. Coronavirus disease 2019 (COVID-19) outbreak. 2020. https://www. who.int/emergencies/diseases/novel-coronavirus-2019. Accessed 18 Feb 2020.

4. Pongpirul WA, Pongpirul K, Ratnarathon AC, Prasithsirikul W. Journey of a Thai taxi driver and novel coronavirus. N Engl J Med. 2020;382(11):1067-8 https://doi.org/10.1056/NEJMc2001621.

5. Li P, Fu J-B, Li K-F, Chen Y, Wang H-L, Liu L-J, et al. Transmission of COVID19 in the terminal stage of incubation period: a familial cluster. Int J Infect Dis. 2020. https://doi.org/10.1016/j.ijid.2020.03.027.

6. Chen N, Zhou M, Dong X, Qu J, Gong F, Han Y, et al. Epidemiological and clinical characteristics of 99 cases of 2019 novel coronavirus pneumonia in 
Wuhan, China: a descriptive study. Lancet. 2020;395(10223):507-13. https:// doi.org/10.1016/s0140-6736(20)30211-7.

7. Cheng ZJ, Shan J. 2019 novel coronavirus: where we are and what we know. Infection. 2020;48(2):155-63. https://doi.org/10.1007/s15010-02001401-y.

8. Wang L, Gao YH, Lou LL, Zhang GJ. The clinical dynamics of 18 cases of COVID-19 outside of Wuhan, China. Eur Respir J. 2020. https://doi.org/10. 1183/13993003.00398-2020

9. Chang D, Lin M, Wei L, Xie L, Zhu G, Dela CC, et al. Epidemiologic and clinical characteristics of novel coronavirus infections involving 13 patients outside Wuhan, China. JAMA. 2020. https://doi.org/10.1001/jama.2020.1623.

10. WHO. Clinical management of severe acute respiratory infection when Novel coronavirus (nCoV) infection is suspected: interim guidance. 2020. https://www.who.int/internalpublications-detail/clinical-management-ofsevere-acute-respiratoryinfection-when-novel-coronavirus-(ncov)-infection-issuspected. Accessed 20 Jan 2020.

11. WHO. Coronavirus disease (COVID-19) technical guidance: laboratory testing for 2019-nCoV in humans. 2020. https://www.who.int/emergencies/diseases/ novel-coronavirus-2019/technical-guidance/laboratory-guidance. Accessed 12 Feb 2020.

12. National Health Commission of the People's Republic of China. Chinese management guideline for COVID-19 (version 6.0). 2020. http://www.nhc. gov.cn/yzygj/s7653p/202002/8334a8326dd94d329df351d7da8aefc2/files/b21 8cfeb1bc54639af227f922bf6b817. Accessed 04 Mar 2020.

13. National Health Commission of China. Guideline of management of COVID19 (version 7). 2020. http://www.nhc.gov.cn/yzygj/s7653p/202003/46c9294 a7dfe4cef80dc7f5912eb1989.shtml. Accessed 04 Mar 2020.

14. Wang Z, Yang B, Li Q, Wen L, Zhang R. Clinical features of 69 cases with coronavirus disease 2019 in Wuhan, China. Clin Infect Dis. 2020. https://doi. org/10.1093/cid/ciaa272.

15. Zhou F, Yu T, Du R, Fan G, Liu Y, Liu Z, et al. Clinical course and risk factors for mortality of adult inpatients with COVID-19 in Wuhan, China: a retrospective cohort study. Lancet. 2020;395(10229):1054-62. https://doi.org/ 10.1016/s0140-6736(20)30566-3.

16. Xu T, Chen C, Zhu Z, Cui M, Chen C, Dai H, et al. Clinical features and dynamics of viral load in imported and non-imported patients with COVID19. Int J Infect Dis. 2020;94:68-71. https://doi.org/10.1016/j.jijd.2020.03.022.

17. Du W, Yu J, Wang H, Zhang X, Zhang S, Li Q, et al. Clinical characteristics of COVID-19 in children compared with adults in Shandong Province, China. Infection. 2020. https://doi.org/10.1007/s15010-020-01427-2

18. Li Q, Guan X, Wu P, Wang X, Zhou L, Tong Y, et al. Early transmission dynamics in Wuhan, China, of novel coronavirus-infected pneumonia. N Engl J Med. 2020;382(13):1199-207. https://doi.org/10.1056/NEJMoa2001316.

19. Phelan A, Katz R, Gostin LJ. The novel coronavirus originating in Wuhan China: challenges for Global Health governance. JAMA. 2020. https://doi. org/10.1001/jama.2020.1097.

20. Qian GQ, Yang NB, Ding F, Ma AHY, Wang ZY, Shen YF, et al. Epidemiologic and Clinical Characteristics of 91 Hospitalized Patients with COVID-19 in Zhejiang, China: A retrospective, multi-centre case series. QJM. 2020; hcaa089. https://doi.org/10.1093/qjmed/hcaa089.

21. Sanz F, Gimeno C, Lloret T, Tormo N, Briones M, Fernandez E, et al. Relationship between the presence of hypoxemia and the inflammatory response measured by C-reactive protein in bacteremic pneumococcal pneumonia. Eur Respir J. 2011;38:2492.

22. Wang D, Hu B, Hu C, Zhu F, Liu X, Zhang J, et al. Clinical characteristics of 138 hospitalized patients with 2019 novel coronavirus-infected pneumonia in Wuhan, China. JAMA. 2020. https://doi.org/10.1001/jama.2020.1585.

23. Guan WJ, Ni ZY, Hu Y, Liang WH, Ou CQ, He JX, et al. Clinical characteristics of coronavirus disease 2019 in China. N Engl J Med. 2020. https://doi.org/10. 1056/NEJMoa2002032

24. Lian J, Jin X, Hao S, Cai H, Zhang S, Zheng L, et al. Analysis of epidemiological and clinical features in older patients with Corona virus disease 2019 (COVID-19) out of Wuhan. Clin Infect Dis. 2020. https://doi.org/ 10.1093/cid/ciaa242.

25. WHO. Report of the WHO-China Joint Mission on Coronavirus Disease 2019 (COVID-19). 2020. https://www.who.int/docs/default-source/coronaviruse/ who-china-joint-mission-on-covid-19-final-report.pdf. Accessed 26 Mar 2020.

26. Zhang J, Wu J, Sun X, Xue H, Shao J, Cai W, et al. Associations of hypertension with the severity and fatality of SARS-CoV-2 infection: a metaanalysis. Epidemiol Infect. 2020;148:e106. https://doi.org/10.1017/ S095026882000117X.
27. Zheng YY, Ma YT, Zhang JY, Xie X. COVID-19 and the cardiovascular system. Nat Rev Cardiol. 2020;17(5):259-60. https://doi.org/10.1038/s41569-020-0360-5.

28. Wan S, Yi Q, Fan S, Lv J, Zhang X, Guo L, et al. Characteristics of lymphocyte subsets and cytokines in peripheral blood of 123 hospitalized patients with 2019 novel coronavirus pneumonia (NCP). medRxiv 2020; 2020. https://doi. org/10.1101/2020.02.10.20021832.

29. Chen G, Wu D, Guo W, Cao Y, Huang D, Wang H, et al. Clinical and immunologic features in severe and moderate coronavirus disease 2019. J Clin Invest. 2020. https://doi.org/10.1172/jci137244.

30. Liu W, Zhao M, Liu K, Xu K, Wong G, Tan W, et al. T-cell immunity of SARSCoV: implications for vaccine development against MERS-CoV. Antivir Res. 2017;137:82-92. https://doi.org/10.1016/j.antiviral.2016.11.006.

31. Wang D, Yin Y, Hu C, Liu X, Zhang X, Zhou S, et al. Clinical course and outcome of 107 patients infected with the novel coronavirus, SARS-CoV-2, discharged from two hospitals in Wuhan, China. Crit Care. 2020;24(1):188. https://doi.org/10.1186/s13054-020-02895-6.

32. Jiang $Y$, He $S$, Zhang $C$, Wang $X$, Chen $X$, Jin $Y$, et al. Clinical characteristics of 60 discharged cases of 2019 novel coronavirus-infected pneumonia in Taizhou, China. Ann Transl Med. 2020;8(8):547. https://doi.org/10.21037/atm. 2020.04.20.

33. Zhang YT, Deng AP, Hu T, et al. Clinical outcomes of COVID-19 cases and influencing factors in Guangdong Province. Zhonghua Liu Xing Bing Xue Za Zhi. 2020;41(0):E057. https://doi.org/10.3760/cma.j.cn112338-2020031800378.

34. Cai Q, Huang D, Ou P, Yu H, Zhu Z, Xia Z, et al. COVID-19 in a designated infectious diseases hospital outside Hubei Province, China. Allergy. 2020. https://doi.org/10.1111/all.14309.

\section{Publisher's Note}

Springer Nature remains neutral with regard to jurisdictional claims in published maps and institutional affiliations.
Ready to submit your research? Choose BMC and benefit from:

- fast, convenient online submission

- thorough peer review by experienced researchers in your field

- rapid publication on acceptance

- support for research data, including large and complex data types

- gold Open Access which fosters wider collaboration and increased citations

- maximum visibility for your research: over $100 \mathrm{M}$ website views per year

At BMC, research is always in progress.

Learn more biomedcentral.com/submissions 